\title{
All-cause mortality in a nationwide cohort of childhood-onset diabetes in Norway 1973-2013
}

\author{
Vibeke Gagnum ${ }^{1,2}$ - Lars C. Stene ${ }^{2,3} \cdot$ Leiv Sandvik ${ }^{4}$ Morten W. Fagerland ${ }^{4}$. \\ Pål R. Njølstad ${ }^{5,6}$ • Geir Joner ${ }^{1,2,7}$ • Torild Skrivarhaug ${ }^{1,2,7,8}$
}

Received: 24 February 2015 / Accepted: 27 April 2015 / Published online: 14 May 2015

(C) Springer-Verlag Berlin Heidelberg 2015

\begin{abstract}
Aims/hypothesis The aim of this study was to assess the association between all-cause mortality and sex, age at diagnosis and year of diagnosis in Norwegian patients with childhoodonset diabetes.

Methods The study was based on the nationwide, populationbased Norwegian Childhood Diabetes Registry, which includes all newly diagnosed cases of childhood-onset diabetes at age 0-14 years in 1973-1982 and 1989-2012 $(n=7,884)$. Patients were followed until date of death, emigration or 30 September 2013.

Results Among the 7,884 patients, representing 132,420 person-years, $249(3.2 \%)$ died during a mean follow-up of 16.8

Electronic supplementary material The online version of this article (doi:10.1007/s00125-015-3623-7) contains peer-reviewed but unedited supplementary material, which is available to authorised users.
\end{abstract}

Vibeke Gagnum

Vibeke.Gagnum@ous-hf.no

1 Department of Paediatrics, Oslo University Hospital, PO Box 4950, Nydalen, N-0424 Oslo, Norway

2 Oslo Diabetes Research Centre, Oslo, Norway

3 Division of Epidemiology, Norwegian Institute of Public Health, Oslo, Norway

4 Oslo Centre for Biostatistics and Epidemiology, Research Support Services, Oslo University Hospital, Oslo, Norway

5 KG Jebsen Center for Diabetes Research, Department of Clinical Science, University of Bergen, Bergen, Norway

6 Department of Paediatrics, Haukeland University Hospital, Bergen, Norway

7 Institute of Clinical Medicine, University of Oslo, Oslo, Norway

8 Norwegian Childhood Diabetes Registry, Department of Paediatrics, Oslo University Hospital, Oslo, Norway (range $0.0-40.7)$ years. The standardised mortality ratio (SMR) for the total cohort was 3.6 (95\% CI 3.1, 4.0), increasing by attained age. Absolute mortality was significantly lower in females than in males (HR 0.50 [95\% CI 0.38, 0.65]), although the SMRs were similar. Cox regression analysis showed a significant decrease in mortality of $49 \%$ (HR 0.51 [95\% CI 0.28, 0.93]) for those diagnosed in 1999-2012 compared with those diagnosed in 1973-1982 ( $p=0.03)$.

Conclusions/interpretation In spite of improved diabetes care, mortality is still three to four times higher in those with childhood-onset diabetes compared with the general population in Norway. However, absolute mortality has declined among children diagnosed most recently (1999-2012) compared with those diagnosed in the earliest period (1973-1982).

Keywords Childhood-onset diabetes · Cohort study • Mortality · Type 1 diabetes

\section{Abbreviations \\ NCDR Norwegian Childhood Diabetes Registry \\ SMR Standardised mortality ratio}

\section{Introduction}

Despite advances in treatment, type 1 diabetes is still associated with a considerable risk of premature mortality, resulting from both acute and chronic complications [1-6]. Mortality varies markedly between countries, and there are indications that countries with a lower incidence of type 1 diabetes have higher absolute and relative mortality compared with high incidence countries [7-9]. For instance, long-term mortality in Finland, a high incidence country (standardised mortality ratio [SMR] 3.7), was lower than in Japan, a low incidence 
country (SMR 12.9) [8]. A recent publication from Japan confirms that relative mortality remains high (SMR 10.7) at 35 years of follow-up [10]. Along with Finland and Sweden, Norway has one of the highest incidences of childhood-onset type 1 diabetes in the world [11]. SMR was 3.6 in a recent Finnish study assessing mortality in a nationwide, populationbased cohort of childhood-onset ( $<15$ years) diabetes covering the period 1970-2007 [4].

Diabetes treatment has improved markedly during the last three decades, with self-monitoring of blood glucose, multiple daily injection regimens, new technology such as insulin pumps and continuous glucose monitoring, and improved treatment of acute and long-term complications [12-15]. Several studies have reported decreasing mortality rates in longterm follow-up of cohorts diagnosed during the 1960s and 1970s [5, 8, 16-18]. A newly published systematic review assessing mortality in type 1 diabetes documented less marked excess mortality in more recent studies [19]. A recent Scottish study estimated a lower life expectancy compared with that of the general population [20]. Long-term follow-up of patients with type 1 diabetes in the Diabetes Control and Complications Trial/Epidemiology of Diabetes Interventions and Complications (DCCT/EDIC) showed a modestly lower mortality rate in those initially receiving intensive therapy compared with those receiving conventional therapy [21], and a Swedish register study reported that the risk of mortality increased with increasing $\mathrm{HbA}_{1 \mathrm{c}}$ [22]. Two previous studies from Norway have shown that mortality in childhood-onset type 1 diabetes diagnosed in 1973-1982 was elevated compared with that in the general population; however, these studies included no information about trend in mortality $[1,2]$.

The aim of this study was to assess the association between all-cause mortality and sex, age at diagnosis and year of diagnosis in patients with childhood-onset diabetes in a nationwide, population-based cohort in Norway, covering the period 1973-2013.

\section{Methods}

Subjects and study design The study is based on data from the nationwide, population-based Norwegian Childhood Diabetes Registry (NCDR) [23-25]. The current analysis includes two nationwide cohorts of 7,884 individuals with newly diagnosed childhood-onset diabetes (54\% males, $46 \%$ females) during 1973-1982 and 1989-2012, followed to 2013 (Fig. 1). Data were not collected nationwide in the period 1983-1988; this period was therefore excluded from the study. The mortality of individuals diagnosed during 19731982 was published by Joner and Patrick [1] and Skrivarhaug et al [2]; in the present study the same cohort was followed for a further 10.7 years, representing 82 new deaths (Fig. 1). The mortality of individuals diagnosed in 1989-2003, followed until December 2005, was published as part of the EURODIAB study [3]. These individuals have now been followed to 30 September 2013. Mortality data for those diagnosed during 2004-2012 have not been published. In Norway all children diagnosed with type 1 diabetes are referred to a hospital paediatric department. Since the NCDR was established in 1989 all paediatric departments have reported newly diagnosed cases based on informed consent; the ascertainment level of NCDR is high (Fig. 1) [23, 25]. Data on new incident cases in 1973-1982 were registered retrospectively using identical methods, for the two 5 year periods, in 1978 (1973-1977) and 1984 (1978-1982) [23]. Type 2 diabetes diagnosed between 0 and 14 years of age is infrequent in Norway. According to data from the NCDR, patients with type 2 diabetes represent less than $1 \%$ of children and adolescents treated in paediatric departments [26]. For the purposes of this study all individuals aged $<15$ years at diagnosis and treated with insulin from the date of diagnosis were classified as having type 1 diabetes according to EURODIAB criteria [3]. Since 2002, patients in the NCDR have been screened for monogenic diabetes. Monogenic diabetes accounts for less than $2 \%$ of patients in this age group [27]. We excluded all individuals who were likely to have type 2 diabetes and those known to have monogenic diabetes. Survival or emigration status was determined as of 30 September 2013, by linking the NCDR database to the National Population Register.

Data analysis We used Stata version 13 (StataCorp LP, College Station, TX, USA) and SPSS version 21.0 (SPSS, Chicago, IL, USA) for data handling and analyses. The follow-up period for each patient was calculated from the date of the first insulin injection to the date of death, emigration or 30 September 2013, whichever occurred first. The diagnosis period was split into three time periods, 1973-1982, 1989-1998 and 1999-2012, to assess temporal trends in mortality risk up to 14 years after diagnosis. We estimated the cumulative mortality (probability of death) by years from diagnosis as 1 minus the Kaplan-Meier estimator. When comparing survival curves we used the logrank test. We also used years since diagnosis as the timescale in Cox regression models to estimate unadjusted and adjusted HRs with 95\% CIs for the association between mortality and age at diagnosis, sex and time periods. Mortality in the study cohort was compared with mortality in the general population in Norway by estimating SMR and mortality rate differences. SMRs were calculated by attained age as the ratio of the observed to the expected number of deaths using mortality rates in the general Norwegian population. Since the age composition of the three periods of diagnosis cohorts are different, and SMR differs by attained age, we estimated ageadjusted SMRs with 95\% CIs for the three cohorts by first stratifying by 10 year attained age groups in each cohort, and then pooling the stratum-specific SMRs using inverse variance weights (Mantel-Haenszel method). We tested for 
Fig. 1 Flow chart illustrating the patients included in the study and the study design. Vital and emigration status for all was ascertained up to 30 September 2013 by register linkage of the NCDR to the National Population Register via a unique identification number. ${ }^{a}$ Ascertainment level $>98 \%$ [23]

${ }^{\mathrm{b}}$ Ascertainment level 92\% [25]

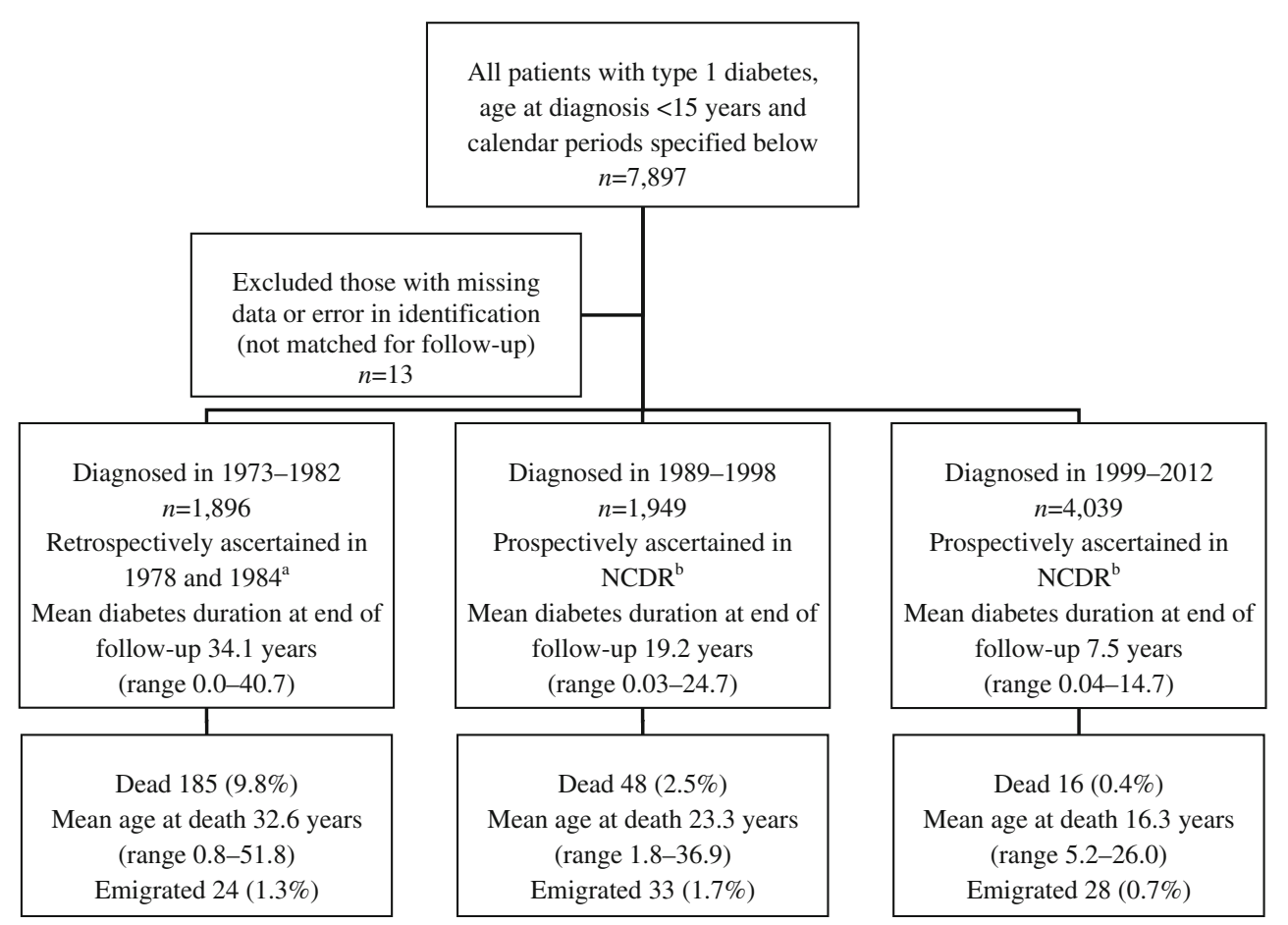

significant trends over attained age and period of diagnosis, before and after mutual adjustment, using Poisson regression models with number of deaths as the dependent variable and $\log _{e}$ (number of expected deaths) as the offset. Mortality rates in 1 year age groups for each sex and each calendar year from 1973 to 2013 were obtained from Statistics Norway (www. ssb.no/en, accessed 1 April 2014). The time each patient spent within each age band and calendar year contributed to the total person-years (data obtained using the stsplit command in Stata). A significance level of 5\% was used. The study protocol was approved by the regional ethics committee.

\section{Results}

Among the 7,884 patients, representing 132,420 person-years, $249(3.2 \%)$ died (174 [4.1\%] males and 75 [2.1\%] females) during a mean follow-up of 16.8 (range 0-40.7) years (Fig. 1). Mean age at diagnosis was 8.8 (range 0.09-14.99) years. Mean age at death was 29.9 (range 0.8-51.8) years and was similar for men and women. The highest attained age during follow-up was 55 years. The composition of the three diagnosis cohorts was very similar regarding sex and age at diagnosis. The youngest person who died was diagnosed with diabetes at the age of 2 months, used insulin from diagnosis, and died at the age of 9 months. There were two deaths within 2 weeks of diabetes diagnosis, and five deaths within the first year. All deaths, including the two deaths close to the date of diagnosis, were included in the analysis.
Absolute mortality The overall mortality rate in the diabetes cohort was 1.88 per 1,000 person-years $(95 \% \mathrm{CI}$ $1.66,2.13$ ) (Table 1$)$. The mortality rate was significantly higher in males than in females $(2.44 / 1,000$ vs $1.22 /$ $1,000$; rate ratio $2.00 ; 95 \%$ CI 1.52, 2.61; $p<0.001)$. The mortality rate was also higher in individuals aged 10-14 years at diagnosis compared with those aged 0 9 years at diagnosis $(2.57 / 1,000$ vs $1.36 / 1,000$; rate ratio 1.90; 95\% CI 1.47, 2.43; $p<0.001)$. Similar results were obtained in Kaplan-Meier analyses (Fig. 2b, c) and Cox regression models (Table 1) of the associations between mortality and sex and age at diagnosis.

Estimated cumulative mortality according to diabetes duration was $1.5 \%(95 \%$ CI $1.3 \%, 1.8 \%)$ at 15 years, $4.5 \%(95 \%$ CI $3.7 \%, 5.2 \%)$ at 25 years, and $9.1 \%$ (95\% CI 7.9\%, 10.3\%) at 35 years (Fig. 2a). The 14 year cumulative mortality in the 1973-1982, 1989-1998 and 1999-2012 diagnosis cohorts was 2.0\% (95\% CI $1.4 \%$, $2.6 \%), 1.5 \%(95 \%$ CI $0.9 \%, 2.1 \%)$ and $1.0 \%$ (CI $95 \%$ $0.4 \%, 1.6 \%$ ), respectively (Fig. $2 \mathrm{~d}$ ). There was a significant, decreasing trend in mortality (logrank test for trend, $p=0.018$ ) over the three time periods (Fig. 2d). Cox regression analysis showed a significant decrease in mortality of 49\% for those diagnosed in 1999-2012 compared with those diagnosed in 1973-1982 (Table 1). The overall mortality rate during the first 14 years of follow-up was significantly lower for patients diagnosed in 1999-2012 compared with patients diagnosed in $1973-1982(0.53 / 1,000$ vs $1.33 / 1,000$; rate ratio 0.40 ; $95 \%$ CI $0.22,0.72 ; p<0.01)$. 
Table 1 SMRs, mortality rates (per 1,000 person-years) and HRs in 7,884 patients with type 1 diabetes diagnosed before 15 years of age between 1973 and 2012

\begin{tabular}{|c|c|c|c|c|c|c|}
\hline Variable & Person-years & Observed deaths & Mortality rate & $\begin{array}{l}\text { SMR, } \\
95 \% \text { CI }\end{array}$ & $\begin{array}{l}\text { HR, adjusted }{ }^{\mathrm{a}} \text {, } \\
95 \% \mathrm{CI}\end{array}$ & $p$ value \\
\hline Overall & 132,420 & 249 & 1.88 & $3.6(3.1,4.0)$ & & \\
\hline \multicolumn{7}{|c|}{ Attained age, years } \\
\hline $0-9$ & 15,943 & 6 & 0.38 & $2.1(1.0,4.7)$ & & \\
\hline $10-19$ & 53,865 & 45 & 0.83 & $2.6(2.0,3.5)$ & & \\
\hline $20-29$ & 34,947 & 73 & 2.09 & $3.2(2.5,4.0)$ & & \\
\hline $30-39$ & 19,137 & 74 & 3.86 & $4.7(3.8,6.0)$ & & \\
\hline$\geq 40$ & 8,528 & 51 & 5.98 & $4.4(3.4,5.8)$ & & \\
\hline Males & 71,211 & 174 & 2.44 & $3.5(3.0,4.0)$ & 1 (ref.) & \\
\hline Females & 61,209 & 75 & 1.22 & $3.8(3.0,4.7)$ & $0.50(0.38,0.65)$ & $<0.001$ \\
\hline \multicolumn{7}{|c|}{ Age at diagnosis, years } \\
\hline $0-9$ & 75,193 & 102 & 1.36 & $3.2(2.6,3.9)$ & 1 (ref.) & \\
\hline $10-14$ & 57,227 & 147 & 2.57 & $3.9(3.3,4.6)$ & $1.86(1.45,2.40)$ & $<0.001$ \\
\hline \multicolumn{7}{|l|}{ Diagnosis period } \\
\hline 1973-1982 & 64,647 & 185 & 2.86 & $3.8(3.2,4.4)^{\mathrm{b}}$ & 1 (ref.) & \\
\hline 1989-1998 & 37,494 & 48 & 1.28 & $2.7(1.9,3.6)^{\mathrm{b}}$ & $0.79(0.55,1.14)$ & 0.20 \\
\hline 1999-2012 & 30,279 & 16 & 0.53 & $2.2(1.0,3.5)^{\mathrm{b}}$ & $0.51(0.28,0.93)$ & 0.03 \\
\hline
\end{tabular}

${ }^{\text {a }}$ Sex, age at diagnosis and diagnosis period are included simultaneously in the regression model, with time since diagnosis as the time variable; adjusted and unadjusted HRs were very similar (unadjusted HRs not shown)

${ }^{\mathrm{b}}$ Adjusted for attained age

${ }^{*} p$ value for adjusted HRs. Test for trend over diagnosis periods up to 14 years after diagnosis in adjusted Cox regression, $p=0.025$

Mortality relative to the general population in Norway Mortality in the entire cohort was 3.6 times higher than mortality in the general population in Norway $(95 \%$ CI 3.1, 4.0). When stratified by 10 year age groups, SMRs increased by increasing attained age and were significantly elevated in all 10 year age groups (Table 1 and Fig. 3a). SMRs for men and women were similar overall (3.5 and 3.8 for men and women, respectively) and in all 10 year age groups (Table 1 and
Fig. 3b). The SMR for patients diagnosed at 10-14 years was not significantly different from that for patients diagnosed at 0-9 years (3.9 vs 3.2). This result did not change when we stratified the analyses by 10 year age groups and sex (Table 1 and Fig. 3c). The SMRs showed a declining tendency from 3.8 to 2.2 over the three time periods of diagnosis (Table 1, Fig. 3d); however, this was not statistically significant.
Fig. 2 Cumulative mortality in 7,884 patients with type 1 diabetes diagnosed before 15 years of age between 1973 and 2012. (a) With $95 \%$ CI. (b) By sex, $p<0.001$. Dashed line, males; solid line, females. (c) By age at diagnosis, $p<0.001$. Solid line, age at diagnosis $10-14$ years; dashed line, age at diagnosis $0-9$ years. (d) By time period of diagnosis, $p=0.018$. Dotted line, 1973-1982; dashed line, 19891998; solid line, 1999-2012. $p$ values in (b) and (c) were calculated using the logrank test; in (d) the logrank test, test for trend
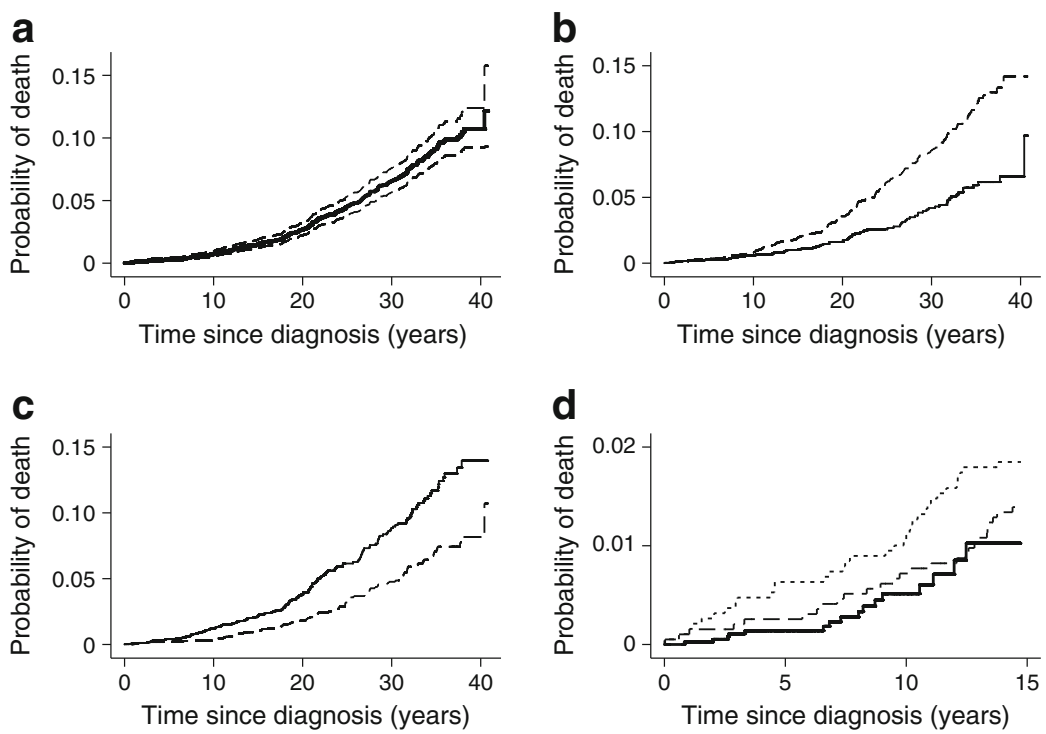

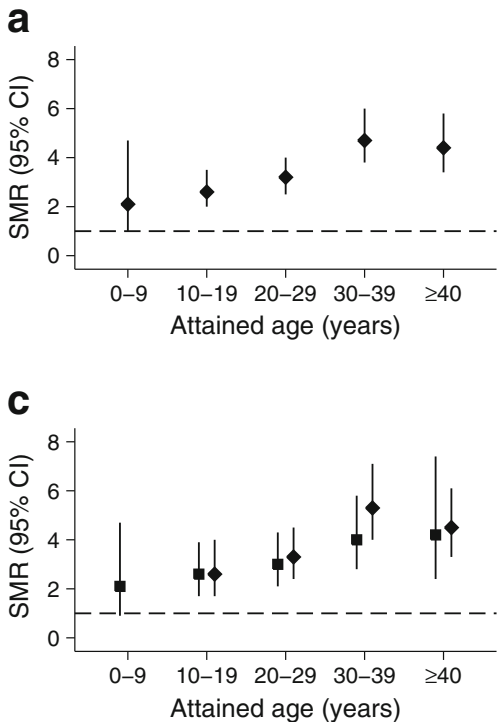

Fig. 3 SMRs in 7,884 patients with type 1 diabetes diagnosed before 15 years of age between 1973 and 2012 presented in 10 year age groups and by calendar period of diagnosis. (a) Overall. (b) By sex. Black squares, males; black diamonds, females. (c) By age at diagnosis. Black squares, 0-9 years; black diamonds, 10-14 years. (d) For each calendar

Finally, we estimated the absolute mortality rate difference for men and women by subtracting the mortality rate of the general population in Norway, with the corresponding age and calendar time, from the mortality rate of the diabetic population. For men we estimated 17 extra deaths per 10,000 personyears at risk, and for women we estimated nine extra deaths per 10,000 person-years at risk. The highest risk difference was in the age group $\geq 40$ years, for which men had an estimated 69 extra deaths per 10,000 person-years at risk and women had an estimated 25 extra deaths per 10,000 personyears at risk. Absolute mortality rates with $95 \%$ CIs for males and females in our cohort and in the general population in Norway, stratified by calendar periods, are shown in electronic supplementary material (ESM) Fig. 1a-d.

\section{Discussion}

Our key finding was that the mortality of individuals with childhood-onset diabetes was 3.6 times higher than that of the general population in Norway. Another novel finding was a significantly decreasing trend in absolute mortality up to 14 years after diagnosis during 1973-2013.

One of the main strengths of this study is that it is a large, population-based, nationwide cohort study with a high degree of ascertainment and long follow-up. The cohort represents a quite homogenous population of almost exclusively ethnic Norwegians with good access to a public healthcare system $[26,28]$. The main limitation of our study is that we did not have information on the causes of death or clinical data from
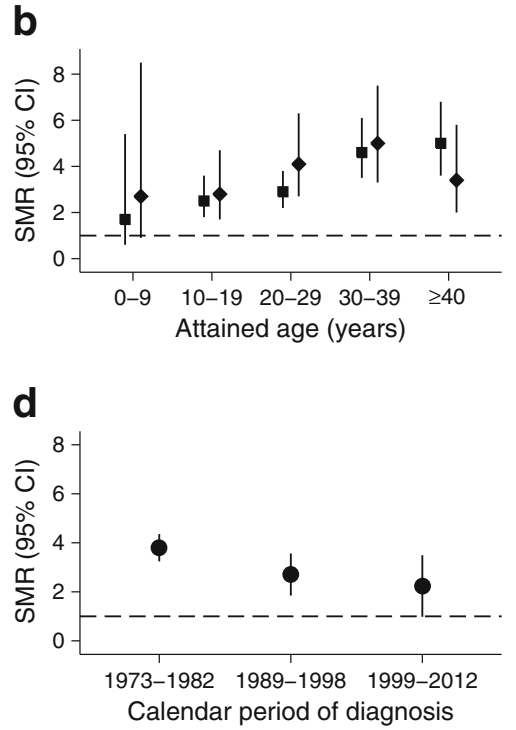

period of diagnosis. Because of the difference in SMR by attained age and the difference in the distribution of attained age in the three cohorts in (d), the SMRs were additionally adjusted for attained age using the MantelHaenszel method

the subjects such as $\mathrm{HbA}_{1 \mathrm{c}}$. Also, when assessing mortality trends, a limitation was the short follow-up time and small number of deaths in the most recently diagnosed cohort. This emphasises the importance of long-term follow-up to ascertain trends in mortality. Another limitation could be the fact that incidence data for the diagnosis period 1973-1982 were collected retrospectively in the early 1980s. However, the ascertainment level of this cohort was high, suggesting that this most likely did not affect the results [23].

It is difficult to compare mortality between countries and study populations. Methods, study populations, length of follow-up, and mortality in the background population tend to differ across studies. A recent systematic review of excess mortality in type 1 diabetes diagnosed in childhood and adolescence found no relationship between a country's incidence of diabetes and SMRs [19]. The SMR in our cohort is very similar to that in a Finnish cohort of childhood-onset diabetes (SMR 3.6) [4]. It was shown in a Norwegian publication that for those diagnosed between 1973 and 1982 the SMR was 4.0 after a mean diabetes duration of 24 years [2]. This was similar to what we found when the cohort was followed for a further 10 years (Table 1) and was consistent with findings from other studies where SMRs tended to increase with attained age up to approximately $30-40$ years [6, 16, 22, 29]. For women, the maximum SMR in our study occurred around the same time as that in a Danish study [16], but about 10 years later than was found in two studies from the UK [6, 29]. The increase in SMR by attained age might reflect that the development of chronic diabetic complications, such as cardiovascular disease, resulted in high mortality rates in our cohort compared 
with the general population $[2,29,30]$. However, several studies have shown that mortality relative to the general population decreases after the age of 40-50 years [6, 29, 31, 32]. We had few patients above 50 years of age, so our results cannot be generalised to mortality in an age group higher than this.

Sex differences in mortality Our finding that absolute mortality was twice as high in male compared with female patients, while the SMR was similar, reflects higher mortality in men compared with women in the general population. This fact is in accordance with earlier published data from Norway [2]. By assessing excess mortality as a risk difference, the difference between the sexes remained substantial. Notably, the literature has been inconclusive regarding the impact of sex on both absolute and relative mortality. A recent systematic review compared all-cause mortality in women and men with type 1 diabetes, reporting sex-specific SMRs or HRs based on data from 26 studies. The review concluded that women had a $40 \%$ excess risk of all-cause mortality and twice the excess risk of fatal vascular events compared with men [33]. This result was consistent across the year of study baseline and the duration of follow-up, but some of the diverging results between studies could be explained by differences in background mortality between the sexes. Hence, in studies in which the mortality rate in women was similar to, or higher than, mortality rates in men, there was a greater excess risk in women than in men. This is in accordance with the results from our study where the mortality rate in the background population was substantially lower for women than for men in these age groups, and the SMR was similar.

Age at diagnosis and mortality We analysed the impact of age at diagnosis on mortality. Several studies have indicated that the prepubertal years of diabetes may contribute less to microvascular complications [34-36], but the opposite has also been reported [37]. Although we did not have data on pubertal status, we divided age at diagnosis into two groups representing a rough categorisation into prepubertal $(0$ 9 years) and pubertal (10-14 years), as has also been done in other recent publications $[5,36]$. While cumulative mortality was significantly higher in those diagnosed at 10-14 years, the SMR was not significantly different in the two groups (SMR 3.2 vs 3.9). This may probably be explained by the fact that those diagnosed at an older age have a systematically higher age during follow-up: the mean age at the end of follow-up in the group diagnosed at age 10-14 years was 29.1 vs 22.9 years for those diagnosed at age $0-9$ years. These findings are consistent with other studies from Finland and Japan $[4,8]$.

Time trends in mortality Management of type 1 diabetes has improved during recent decades, and guidelines are readily available. Multiple daily injection therapy and selfmonitoring of blood glucose were introduced in the 1980s. Most patients in our cohorts have likely benefited from this, but probably to a larger degree in those diagnosed more recently. Two recent studies have estimated the life expectancy of patients with type 1 diabetes in the United States and Scotland. Both report lower life expectancy, but, although the results differ between the studies, they both report improvement in life expectancy compared with earlier studies [20,38]. We demonstrated a declining trend in absolute mortality up to 14 years after diagnosis during 1973-2013. While the SMR also tended to decrease over time, it is probably most relevant to emphasise the absolute decline in mortality among patients with type 1 diabetes, in this context with a very low and declining mortality in the background population. Several studies have reported temporal improvements in mortality $[4,5,32,38]$. However, studies differ in populations, diagnosis periods, duration of diabetes and age at diagnosis and this makes it difficult to directly compare studies with each other. Morgan et al showed that the excess mortality in type 1 diabetes diagnosed in childhood and adolescence was less marked in more recent studies and in countries with lower infant mortality and higher health expenditure, which suggests potential explanations for the differences [19].

In conclusion, we have demonstrated that mortality in childhood-onset diabetes is still considerably increased in Norway and varies with attained age compared with that in the general population. SMRs were similar in males and females, but excess mortality assessed by risk difference was higher in men. We found a significantly decreasing trend in absolute mortality up to 14 years of follow-up over the time period of diagnosis.

Acknowledgements The authors thank all the members of the Norwegian Childhood Diabetes Study Group for their contribution.

Some of the data were presented at the 40th Annual Conference of the International Society for Pediatric and Adolescent Diabetes (ISPAD), 3-6 September 2014, Toronto, Canada.

Funding The South-Eastern Norway Regional Health Authority funded the study. PRN was supported by funds from the University of Bergen, the Research Council of Norway, Helse Vest, and the KG Jebsen Foundation.

Duality of interest No conflicts of interest relevant to this article were reported.

Contribution statement VG wrote the manuscript and organised and analysed the data. TS developed the study concept, initiated the study, collected data and supervised the study. LCS supervised the data analysis. GJ contributed to initiation of the study. LS and MWF contributed to the data analysis. PRN helped with data collection. All authors contributed to interpretation of the results and to the discussion, critically reviewed the paper and approved the final version of the manuscript. TS is responsible for the integrity of the work as a whole. 


\section{References}

1. Joner G, Patrick S (1991) The mortality of children with type 1 (insulin-dependent) diabetes mellitus in Norway, 1973-1988. Diabetologia 34:29-32

2. Skrivarhaug T, Bangstad HJ, Stene LC, Sandvik L, Hanssen KF, Joner G (2006) Long-term mortality in a nationwide cohort of childhood-onset type 1 diabetic patients in Norway. Diabetologia 49:298-305

3. Patterson CC, Dahlquist G, Harjutsalo V et al (2007) Early mortality in EURODIAB population-based cohorts of type 1 diabetes diagnosed in childhood since 1989. Diabetologia 50:2439-2442

4. Harjutsalo V, Forsblom C, Groop PH (2011) Time trends in mortality in patients with type 1 diabetes: nationwide population based cohort study. BMJ 343:d5364

5. Secrest AM, Becker DJ, Kelsey SF, Laporte RE, Orchard TJ (2010) All-cause mortality trends in a large population-based cohort with long-standing childhood-onset type 1 diabetes: the Allegheny County type 1 diabetes registry. Diabetes Care 33:2573-2579

6. Laing SP, Swerdlow AJ, Slater SD et al (1999) The British Diabetic Association Cohort Study, I: all-cause mortality in patients with insulin-treated diabetes mellitus. Diabet Med 16:459-465

7. Diabetes Epidemiology Research International Mortality Study Group (1991) Major cross-country differences in risk of dying for people with IDDM. Diabetes Care 14:49-54

8. Asao K, Sarti C, Forsen T et al (2003) Long-term mortality in nationwide cohorts of childhood-onset type 1 diabetes in Japan and Finland. Diabetes Care 26:2037-2042

9. Matsushima M, Laporte RE, Maruyama M, Shimizu K, Nishimura $\mathrm{R}$, Tajima N (1997) Geographic variation in mortality among individuals with youth-onset diabetes mellitus across the world. DERI Mortality Study Group. Diabetes Epidemiology Research International. Diabetologia 40:212-216

10. Morimoto A, Onda Y, Nishimura R, Sano H, Utsunomiya K, Tajima N (2013) Cause-specific mortality trends in a nationwide population-based cohort of childhood-onset type 1 diabetes in Japan during 35 years of follow-up: the DERI Mortality Study. Diabetologia 56:2171-2175

11. Patterson C, Guariguata L, Dahlquist G, Soltesz G, Ogle G, Silink M (2014) Diabetes in the young - a global view and worldwide estimates of numbers of children with type 1 diabetes. Diabetes Res Clin Pract 103:161-175

12. Chiang JL, Kirkman MS, Laffel LM, Peters AL (2014) Type 1 diabetes through the life span: a position statement of the American Diabetes Association. Diabetes Care 37:2034-2054

13. Pambianco G, Costacou T, Ellis D, Becker DJ, Klein R, Orchard TJ (2006) The 30-year natural history of type 1 diabetes complications: the Pittsburgh Epidemiology of Diabetes Complications Study experience. Diabetes 55:1463-1469

14. Hovind P, Tarnow L, Rossing K et al (2003) Decreasing incidence of severe diabetic microangiopathy in type 1 diabetes. Diabetes Care 26:1258-1264

15. Nordwall M, Bojestig M, Arnqvist HJ, Ludvigsson J (2004) Declining incidence of severe retinopathy and persisting decrease of nephropathy in an unselected population of type 1 diabetes - the Linköping Diabetes Complications Study. Diabetologia 47: 1266-1272

16. Borch-Johnsen K, Kreiner S, Deckert T (1986) Mortality of type 1 (insulin-dependent) diabetes mellitus in Denmark: a study of relative mortality in 2930 Danish type 1 diabetic patients diagnosed from 1933 to 1972. Diabetologia 29:767-772

17. McNally PG, Raymond NT, Burden ML et al (1995) Trends in mortality of childhood-onset insulin-dependent diabetes mellitus in Leicestershire: 1940-1991. Diabet Med 12:961-966
18. Nishimura R, Laporte RE, Dorman JS, Tajima N, Becker D, Orchard TJ (2001) Mortality trends in type 1 diabetes. The Allegheny County (Pennsylvania) Registry 1965-1999. Diabetes Care 24:823-827

19. Morgan E, Cardwell CR, Black CJ, McCance DR, Patterson CC (2015) Excess mortality in type 1 diabetes diagnosed in childhood and adolescence: a systematic review of population-based cohorts. Acta Diabetol. doi:10.1007/s00592-014-0702-Z

20. Livingstone SJ, Levin D, Looker HC et al (2015) Estimated life expectancy in a Scottish cohort with type 1 diabetes, 2008-2010. JAMA 313:37-44

21. Orchard TJ, Nathan DM, Zinman B et al (2015) Association between 7 years of intensive treatment of type 1 diabetes and longterm mortality. JAMA 313:45-53

22. Lind M, Svensson AM, Kosiborod M et al (2014) Glycemic control and excess mortality in type 1 diabetes. N Engl J Med 371:1972-1982

23. Joner G, Søvik O (1989) Increasing incidence of diabetes mellitus in Norwegian children 0-14 years of age 1973-1982. Diabetologia 32:79-83

24. Aamodt G, Stene LC, Njølstad PR, Søvik O, Joner G (2007) Spatiotemporal trends and age-period-cohort modeling of the incidence of type 1 diabetes among children aged $<15$ years in Norway 1973-1982 and 1989-2003. Diabetes Care 30: 884-889

25. Skrivarhaug T, Stene LC, Drivvoll AK, Strøm H, Joner G (2014) Incidence of type 1 diabetes in Norway among children aged 0-14 years between 1989 and 2012: has the incidence stopped rising? Results from the Norwegian Childhood Diabetes Registry. Diabetologia 57:57-62

26. T Skrivarhaug, SJ Kummernes, AK Drivvoll (2013) The Norwegian Childhood Diabetes Registry - annual report 2013. Available from www.oslodiabetes.no/wp-content/uploads/2014/ 10/Read-annual-report.pdf

27. Irgens HU, Molnes J, Johansson BB et al (2013) Prevalence of monogenic diabetes in the population-based Norwegian Childhood Diabetes Registry. Diabetologia 56:1512-1519

28. Eidem I, Vangen S, Hanssen KF et al (2011) Perinatal and infant mortality in term and preterm births among women with type 1 diabetes. Diabetologia 54:2771-2778

29. Livingstone SJ, Looker HC, Hothersall EJ et al (2012) Risk of cardiovascular disease and total mortality in adults with type 1 diabetes: Scottish registry linkage study. PLoS Med 9:e1001321

30. Laing SP, Swerdlow AJ, Slater SD et al (1999) The British Diabetic Association Cohort Study, II: cause-specific mortality in patients with insulin-treated diabetes mellitus. Diabet Med 16:466-471

31. Soedamah-Muthu SS, Fuller JH, Mulnier HE, Raleigh VS, Lawrenson RA, Colhoun HM (2006) All-cause mortality rates in patients with type 1 diabetes mellitus compared with a non-diabetic population from the UK general practice research database, 19921999. Diabetologia 49:660-666

32. Jørgensen ME, Almdal TP, Carstensen B (2013) Time trends in mortality rates in type 1 diabetes from 2002 to 2011. Diabetologia 56:2401-2404

33. Huxley RR, Peters SA, Mishra GD, Woodward M (2015) Risk of all-cause mortality and vascular events in women versus men with type 1 diabetes: a systematic review and meta-analysis. Lancet Diab Endocrinol 3:198-206

34. Donaghue KC, Fairchild JM, Craig ME et al (2003) Do all prepubertal years of diabetes duration contribute equally to diabetes complications? Diabetes Care 26:1224-1229

35. Kostraba JN, Dorman JS, Orchard TJ et al (1989) Contribution of diabetes duration before puberty to development of microvascular complications in IDDM subjects. Diabetes Care 12:686-693 
36. Svensson M, Nyström L, Schön S, Dahlquist G (2006) Age at onset of childhood-onset type 1 diabetes and the development of end-stage renal disease: a nationwide population-based study. Diabetes Care 29:538-542

37. Holl RW, Lang GE, Grabert M, Heinze E, Lang GK, Debatin KM (1998) Diabetic retinopathy in pediatric patients with type-1 diabetes: effect of diabetes duration, prepubertal and pubertal onset of diabetes, and metabolic control. J Pediatr 132:790-794

38. Miller RG, Secrest AM, Sharma RK, Songer TJ, Orchard TJ (2012) Improvements in the life expectancy of type 1 diabetes: the Pittsburgh Epidemiology of Diabetes Complications study cohort. Diabetes 61:2987-2992 